\title{
Maternal and infant health in urban and rural areas in Morocco: Analysis of the preliminary results of the National Survey on Population and Family Health (EPSF 2011)
}

\author{
Abdesslam Boutayeb*, Wiam Boutayeb, Mohamed E. N. Lamlili \\ Laboratory of Stochastic and Deterministic Modelling, Research Unit Associated to CNRST, Faculty of Sciences, University Mo-

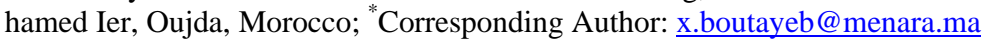

Received 11 May 2012; revised 7 June 2012; accepted 18 June 2012

\section{ABSTRACT}

Background: The last Moroccan population and family health survey (EPSF 2011) was carried out between November 2010 and March 2011. The final report and the whole database are not yet accessible while a preliminary report was released early March 2012. The information given so far does not allow for a complete evaluation of the present health situation in Morocco. However, a partial equity analysis can be devoted to the comparison of health indicators in terms of gender and urban-rural gaps. Method: 1) Questionnaires: a household questionnaire dealt with household characteristics, general health, housing condition and anthropometric data for children less than six years of age. A second questionnaire was devoted specifically to ever married women and dealt with their resources, marriage, reproductive health, family planning, AIDS/SIDA, healthcare and nutrition. 2) Data collection: data were collected through the national survey using a three-stage stratified sampling design to select 640 clusters covering the 16 Moroccan regions. A total of 15,577 households were randomly drawn, providing a sample of 75,061 individuals $(51.1 \%$ females and $48.9 \%$ males) for investigation. 3) Analysis: in this short report, we relied only on partial data released by the Ministry of Health in a preliminary report. We used absolute differences and relative ratios to study the evolution of gender and urban-rural gaps on the basis of socioeconomic indicators. Results and Discussion: The Moroccan population seems to be in the last phase of its demographic transition. The total fertility rate decreased from $\mathbf{5 . 6}$ children per woman in $\mathbf{1 9 8 0}$ to 2.5 in 2011 . The mean age of first marriage went from 24 years for men and 17.5 years for women in 1960 to $\mathbf{3 1 . 5}$ years and 26.3 in 2011 for men and women respectively. The age structure is showing a trend of ageing population. Generally, health indicators related to reproductive and women's health improved noticeably and consequently, maternal and infant mortality also decreased. However, while these achievements are praiseworthy as national averages, they remain insufficient in terms of equitable healthcare and access to health services since there is still a long way to go in order to reduce the huge gender gaps and rural-urban disparities. Conclusion: In this short report, we showed that, as averages, health indicators improved noticeably during the last decade but gender inequality and urban-rural disparities are still challenging health decision makers. Moroccan health decision makers are urged to adopt an equitable health strategy, starting by giving access to data for analysis, monitoring and evaluation.

Keywords: Health Equity; Gender; Rural; Urban; Indicators; Maternal; Infant

\section{INTRODUCTION}

The Moroccan Ministry of Health carries out regular surveys on population and family health. The last National Survey (EPSF 2011) was carried out from November 2010 to March 2011. The final report and the whole database are not yet accessible while a preliminary report was released early March 2012 [1]. The information given so far does not allow for a complete analysis and evaluation of the present health situation in Morocco, 
compared to data yielded by the previous surveys. However, the available data is sufficient for a partial equity analysis in terms of gender and rural-urban gaps. Data of previous demographic health surveys [2] and censuses [3] constitute a valuable capital for the comparison of trends and health indicators. Since the last report released by the WHO commission on social determinants of health in 2008 [4], followed by the Rio political declaration on social determinants of health adopted by head of governments, ministers and government representatives in October 2011 [5], health equity has been put on all agendas and it is supposed to be a shared responsibility requiring the engagement of all sectors of governments and all segments of national and international society in "an all for equity" global action. This preliminary analysis will constitute a cornerstone for a more advanced equity analysis that will allow Moroccan health authorities to evaluate the current health situation in order to adopt cost-effective strategies that improve "health for all" and reduce the gaps between advantaged and disadvantaged populations.

\section{MEHTOD}

\subsection{Questionnaires}

Following the standards questionnaires of PAPFAM, a household questionnaire dealt with household characteristics, general health, housing condition and anthropometric data for children less than six years of age. A second questionnaire was devoted specifically to women and dealt with their resources, marriage, reproductive health, family planning, AIDS/SIDA, healthcare and nutrition.

\subsection{Data Collection}

Data were collected through the national survey using a three-stage stratified sampling design to select 640 clusters (400 in urban areas and 240 in rural areas) covering the 16 Moroccan regions (Figure 1). Then 25 households were randomly drawn from each cluster, providing a total of 15,577 households for investigation. The sample was thus formed of 75,061 people with females representing $51.1 \%$. The second questionnaire concerned 11,069 ever married women aged 15 to 49 .

\subsection{Analysis}

In this short report, we relied only on partial data released by the Ministry of Health in a preliminary report because the whole data is not yet accessible. We used absolute differences and relative ratios to study the evolution of gender and urban-rural gaps on the basis of socioeconomic indicators. Unfortunately, with the limited

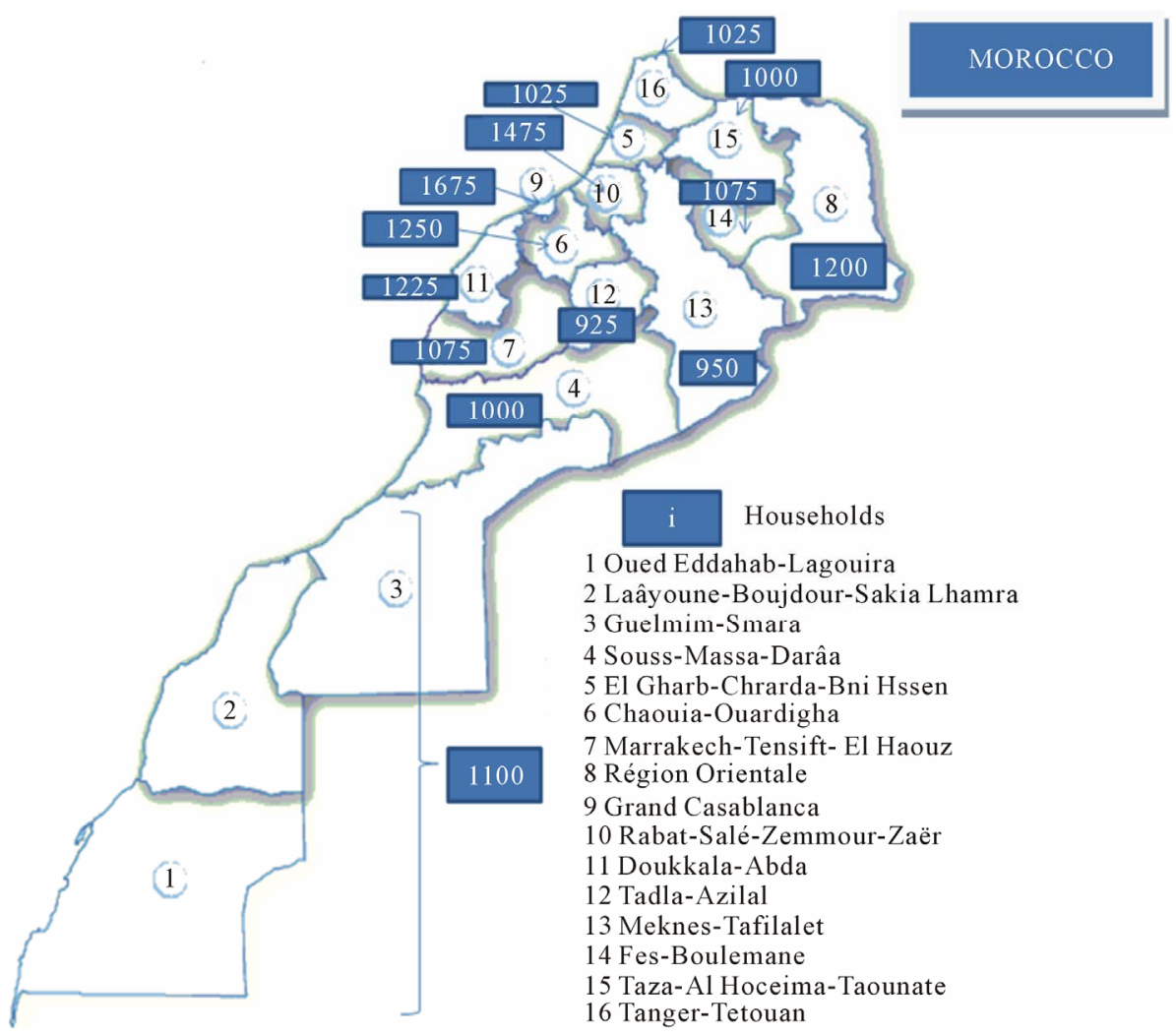

Figure 1. A Moroccan map with regions and numbers of households forming the survey sample. 
data at hand, we were not able to do a complete statistical analysis, using tests confidence intervals and elaborated data analysis.

\section{RESULTS AND DISCUSSION}

\subsection{Demographic Transition}

Beside the economic and political transitions, Morocco is also undergoing epidemiological and demographic transitions. The geographical distribution shifted from a rural to an urban dominance and the annual growth rate decreased from 2.8\% during the decade 1960-1970 to $1.4 \%$ between 1994 and 2004. The mean age of first marriage has been constantly delayed, postponed from 24 years for men and 17.5 years for women in 1960 to 31.4 years and 26.6 in 2011 for men and women respectively (Table 1 ). The delay of first marriage can be explained by a multitude of cultural and socioeconomic factors such as the access of young girls to higher education, unemployment, housing problems, unaffordable expenses of marriage for men (dowry, ceremony, festivity) and high cost of child bringing up [6].

The total fertility rate decreased from 5.6 children per woman in 1980 to 2.5 in 2004 but it remained at the same level during the last decade according the 2011 survey. Consequently, the age structure is indicating a trend of an ageing population. Indeed, the percentage represented by the youngest class $(0-14)$ decreased from $43.6 \%$ in 1980 to $29 \%$ in 2011 while the middle and elderly categories increased respectively from $52.7 \%$ to $64.2 \%$ and from $3.7 \%$ to $6.8 \%$ during the same period of time (Table 2).

\subsection{Illiteracy and Unemployment: Persistent Challenges}

Illiteracy is still challenging decision makers in Morocco though it decreased from $43 \%$ in 2004 to $37.6 \%$ in 2011. Moreover, this problem is affecting inequitably the
Moroccan population. Illiteracy among women (54.7\%) is nearly the double of that of men (30.8\%). Rural populations are more adversely affected by illiteracy (60.5\%) than their urban counterparts (29.4\%). A rural woman is 4.27 more likely to be illiterate than an urban man (for the age category (15 - 24) the ratio reaches 9.27 in 2011). Last but not least, the comparison between 2004 and 2011 data shows that the gender gap as well as the relative ratio between urban and rural areas are persisting or even increasing (Table 3).

During the last years, unemployment has become a major concern worldwide. In Morocco, the 2011 survey indicates that among women aged 15 years and over, the unemployment rate reaches $81 \%$ in cities and $94 \%$ in rural areas, compared to respectively $37 \%$ and $24 \%$ for men.

\subsection{Maternal Health: Towards Further Reduction of Urban-Rural Gaps}

During the last decade, noticeable efforts were devoted by Moroccan health authorities to maternal and infant health in order to achieve the millennium development goals MDG4 and MDG5, stipulating the reduction of child mortality rate and maternal mortality ratio respectively by two thirds and three quarters between 1990 and 2015. In 2011, four years ahead of the deadlines, the results obtained are satisfactory and Morocco is on the track to achieve these two MDGs.

The recent survey shows that $77 \%$ of Moroccan women had prenatal care, compared to $68 \%$ in 2004 . The difference is quite significant between urban (91.6\%) and rural (77.1\%). The percentage of assisted deliveries (61\%) and deliveries happening in health structures (63\%) are nearly the same and show similar differences between rural and urban areas. Finally, the proportion of women having postnatal care remains very low (21.9\%) especially in rural areas (13.3\%) (Table 4). With a slight difference between urban and rural areas, the use of contraceptive

Table 1. Demographic and urban/rural evolution of the Moroccan population [3,6].

\begin{tabular}{|c|c|c|c|c|c|c|c|c|c|}
\hline \multirow[b]{2}{*}{ Year } & \multicolumn{3}{|c|}{ Population (millions) } & \multicolumn{6}{|c|}{ Mean age at first marriage (years) } \\
\hline & Urban (\%) & Rural (\%) & Total & \multicolumn{2}{|c|}{ Urban } & \multicolumn{2}{|c|}{ Rural } & \multicolumn{2}{|c|}{ National } \\
\hline 1960 & 3.4 (29) & $8.2(71)$ & 11.6 & 24 & 17 & 24 & 17 & 24 & 17 \\
\hline 1971 & $5.4(35)$ & $9.9(65)$ & 15.3 & 26 & 21 & 24 & 18 & 25 & 19 \\
\hline 1982 & 8.7 (43) & 11.7 (57) & 20.4 & 28 & 24 & 26 & 21 & 27 & 22 \\
\hline 1994 & $13.4(51)$ & $12.7(49)$ & 26.1 & 31 & 27 & 28 & 24 & 30 & 26 \\
\hline 2004 & $16.5(55)$ & $13.4(45)$ & 29.9 & 32 & 27 & 29 & 25 & 31 & 26 \\
\hline 2011 & $18.5(58)$ & $13.4(42)$ & 31.9 & 33 & 27 & 30 & 26 & 31 & 27 \\
\hline
\end{tabular}


Table 2. Evolution of fertility and age structure in Morocco $[1,2]$.

\begin{tabular}{ccccc}
\hline Survey (year) & $\begin{array}{c}\text { ENFPF } \\
(1980)\end{array}$ & $\begin{array}{c}\text { ENPS } \\
(1992)\end{array}$ & $\begin{array}{c}\text { EPSF } \\
(2004)\end{array}$ & $\begin{array}{c}\text { EPSF } \\
(2011)\end{array}$ \\
\hline Total fertility rate & 5.6 & 4.0 & 2.5 & 2.5 \\
Age structure & & & & \\
$0-14$ & $43.6 \%$ & $39.7 \%$ & $32.0 \%$ & $29.0 \%$ \\
$15-64$ & $52.7 \%$ & $55.6 \%$ & $62.7 \%$ & $64.2 \%$ \\
$65+$ & $3.7 \%$ & $4.6 \%$ & $5.4 \%$ & $6.8 \%$ \\
\hline
\end{tabular}

ENFPF: Enquête Nationale de Fécondité et de Planification Familiale (National Survey on Fecondity and Family Planning); ENPS: Enquête Nationale sur la Population et la Santé (National Survey on Population and Health); EPSF: Enquête sur la Population et al. Santé Familiale (Survey on Population and Family Health).

Table 3. Evolution of gender and urban-rural gaps in illiteracy.

\begin{tabular}{|c|c|c|c|c|}
\hline $\begin{array}{c}\text { Illiteracy } 10 \\
\text { years + }\end{array}$ & $\begin{array}{l}\text { Male } \\
(\%)\end{array}$ & $\begin{array}{c}\text { Female } \\
(\%)\end{array}$ & $\begin{array}{c}\text { Both sexes } \\
\text { (\%) }\end{array}$ & Ratio $\mathrm{F} / \mathrm{M}$ \\
\hline \multicolumn{5}{|l|}{ Year 2004} \\
\hline Urban & 18.8 & 39.5 & 29.4 & 2.11 \\
\hline Rural & 46.0 & 74.5 & 60.5 & 1.62 \\
\hline National & 30.8 & 54.7 & 43.0 & 1.77 \\
\hline Ratio R/U & 2.45 & 1.91 & 2.06 & \\
\hline \multicolumn{5}{|l|}{ Year 2011} \\
\hline Urban & 15.5 & 34.7 & 25.4 & 2.25 \\
\hline Rural & 40.0 & 66.2 & 53.6 & 1.65 \\
\hline National & 26.0 & 48.4 & 37.6 & 1.86 \\
\hline Ratio R/U & 2.58 & 1.90 & 2.11 & \\
\hline
\end{tabular}

Table 4. Women access to health care.

\begin{tabular}{|c|c|c|c|c|}
\hline & $\begin{array}{l}\text { \% of women } \\
\text { who had } \\
\text { prenatal care }\end{array}$ & $\begin{array}{c}\% \text { of deliveries } \\
\text { in health } \\
\text { services }\end{array}$ & $\begin{array}{c}\% \text { of } \\
\text { assisted } \\
\text { deliveries }\end{array}$ & $\begin{array}{c}\text { \% of women } \\
\text { who had } \\
\text { postnatal care }\end{array}$ \\
\hline \multicolumn{5}{|l|}{ Year 2004} \\
\hline Urban & 85 & 83.2 & 85.3 & 16.3 \\
\hline Rural & 48 & 38 & 39.5 & 3.6 \\
\hline National & 68 & 61 & 63 & 6.6 \\
\hline Ratio R/U & 1.77 & 2.18 & 2.16 & 4.5 \\
\hline \multicolumn{5}{|l|}{ Year 2011} \\
\hline Urban & 91.6 & 90.7 & 92.1 & 30.5 \\
\hline Rural & 62.7 & 54.6 & 55.0 & 13.3 \\
\hline National & 77.1 & 72.7 & 73.6 & 21.9 \\
\hline Ratio R/U & 1.46 & 1.66 & 1.67 & 2.31 \\
\hline
\end{tabular}

methods increased from 63\% in 2004 to $67.4 \%$ in 2011. According to the $\mathrm{MOH}$, improvement of accessibility to women's health care resulted in a significant reduction of maternal mortality ratio (MMR) from 227 in 2004 to 112 in 2010 [7].

\subsection{Nutrition and Infant Mortality}

Infant mortality rate and under five mortality rate in 2011 decreased from 40 in 2004 to 28.8 , and from 47 to 30.5 respectively. The gaps between urban and rural areas have been reduced but they are still inadmissible compared to developed countries and some developing countries [4]. Postnatal mortality shows the highest gap between rural and urban with a ratio of 2.4 in 2004 and 1.98 in 2011 (Table 5).

The sample provided a total of 7310 children under five years of age for anthropometric measures. A child was considered as underweight if his or her weight to age was $<2$ SD the median weight to age of the sample. Similarly, children were considered stunting (respectively wasting) if their height to age (respectively weight to height) was $<2$ SD the median of the sample.

The 2011 survey showed that, though the mean proportions of stunting, underweight and wasting children decreased between 2004 and 2011, the ratios rural/urban all increased during the same period of time (Table 6).

\section{STRENGTH AND LIMITATION OF THE STUDY}

The last national survey on population and family health was carried out in 2003/2004. Consequently, the 2011 survey was needed in order to update health and socioeconomic indicators which are indispensable for the elaboration of optimal strategies and efficient policies. However, up to the present time, the Moroccan Ministry of Health has not yet given accessibility to the whole survey data base. Meanwhile, we used the limited available data to show that inequalities must be reduced along with improvement of socioeconomic indicators as averages. We focused on urban-rural gaps but we didn't have sufficient data for analysis and comparison between regions.

\section{CONCLUSION}

In this short report, we showed that health improved noticeably during the last decade but gender inequality and urban-rural disparity are still challenging health decision makers. It should be stressed that beyond the evolution of health indicators as national averages, it is necessary to look at geographical disparities, gender inequalities and other differences between sub-population groups based on income, education, ethnicity and others. 
Table 5. Evolution of urban-rural gaps in infant mortality.

\begin{tabular}{ccccc}
\hline & Neonatal mortality rate & Postnatal mortality rate & Infant mortality rate & Under five mortality rate \\
\hline Year 2004 & 24 & & 33 & 38 \\
Urban & 33 & 9 & 55 & 69 \\
Rural & $\mathbf{1 . 3 7}$ & 22 & $\mathbf{1 . 6 7}$ & $\mathbf{1 . 8 1}$ \\
Ratio R/U & & $\mathbf{2 . 4 0}$ & 23.56 & 25.42 \\
Year 2011 & 16.97 & & 33.57 & 35.07 \\
Urban & 20.52 & 6.59 & $\mathbf{1 . 4 2}$ & $\mathbf{1 . 3 8}$ \\
Rural & $\mathbf{1 . 2 1}$ & 13.05 & $\mathbf{1 . 9 8}$ & \\
Ratio R/U & & &
\end{tabular}

Table 6. Urban-rural differences in child nutrition.

\begin{tabular}{cccc}
\hline & $\begin{array}{c}\text { Stunting } \\
(\%)<2 \text { SD }\end{array}$ & $\begin{array}{c}\text { Underweight } \\
(\%)<2 \text { SD }\end{array}$ & $\begin{array}{c}\text { Wasting } \\
(\%)<2 \text { SD }\end{array}$ \\
\hline Year 2004 & & & \\
Urban & 12.9 & 6.5 & 7.6 \\
Rural & 23.6 & 14.1 & 11.1 \\
National & 18.1 & 9.3 & 10.2 \\
Ratio Rural/Urban & $\mathbf{1 . 8 3}$ & $\mathbf{2 . 1 7}$ & $\mathbf{1 . 4 6}$ \\
Year 2011 & & & \\
Urban & 8.6 & 1.7 & 1.6 \\
Rural & 20.5 & 4.3 & 3.0 \\
National & 14.9 & 3.1 & 2.3 \\
Ratio Rural/Urban & $\mathbf{2 . 3 8}$ & $\mathbf{2 . 5 3}$ & $\mathbf{1 . 8 7}$ \\
\hline
\end{tabular}

Accessibility to the complete database will allow researchers to use various tools (Gini index, concentration index, entropy measures...) in order to evaluate the present health situation in terms of equitable access to health services and healthcare. As indicated by the recent Common Country Assessment report (UN, 2011), gender and socio-spatial inequalities constitute real challenges for Morocco [8]. Consequently, we hope that this preliminary study will convince Moroccan health decision makers to give more importance to equitable strategies, starting by giving access to the whole survey database for a more complete analysis that will foster the monitoring and evaluation of future programmes.

\section{REFERENCES}

[1] Ministère de la Santé, Royaume du Maroc (2011) Direction de la Planification et des ressources financières. Enquête Nationale sur la Population et la Santé Familiale (ENPSF 2011), Rapport Préliminaire.

[2] Moroccan Ministry of Health. Demographic health survey. http://www.measuredhs.com/Publications/Publications-by -country.cfm

[3] Haut commissariat au plan. Recensements. http://www.hcp.ma

[4] Commission on Social Determinants of Health (2008) Closing the gap in a generation: Health equity through action on the social determinants of health. World Health Organization, Geneva.

[5] World conference on social determinants of health (2011). http://www.who.int/sdhconference/declaration/en/

[6] Boutayeb, A. (2011) Social determinants and reproductive health in Morocco. African Journal of Reproductive Health, 15, 57-65.

[7] Ministère de la Santé, Royaume du Maroc and UNFPA (2011) Reducing maternal mortality in Morocco. Sharing Experience and Sustaining Progress 2011.

[8] Untied Nations Morocco (2010) Common country assessment report 2010. 